\title{
3D non-linear finite element analysis of concentrically loaded high strength reinforced concrete column with GFRP bar
}

\author{
Adhi Dharma Prasetyo ${ }^{a}$, Bambang Piscesa ${ }^{a}$, Harun Alrasyid ${ }^{a}$ Dwi Prasetya ${ }^{a}$
}

\begin{abstract}
The use of High Strength Concrete (HSC) material in Reinforced Concrete (RC) column has become widely used. HSC was found to be durable, strong in compression, but it has low ductility. This low ductility of HSC can be improved by providing confinement. However, for HSC with concrete strength higher than $70 \mathrm{MPa}$, additional clause for confinement in ACI 318-19 generates denser arrangement of transverse bars and eventually creates weak planes between the concrete core and the cover. These weak planes can trigger early cover spalling. To reduce the utilization of confining bars, high-strength Glass Fiber Reinforce Polymer (GFRP) bar can be used. However, the performance of GFRP bar varies significantly from their uniaxial behavior in tension or compression to the real performance when it is used as the main reinforcement. For that reason, this paper tries to investigate the behavior of HSC RC column with bars made of conventional steel rebar and with GFRP bars. Due to limited data on the strain gauge reading on the GFRP bars from the available test result, an inverse analysis is carried out to determine the best stress-strain curve for GFRP bars used as the main reinforcement. For that purpose, an inhouse finite element package called 3D-NLFEA is used. From the comparisons, it was found out that the peak load, softening behavior, and the concrete core enhancement prediction agrees well with the test result. From the inverse analysis, only $25 \%$ and $45 \%$ of the GFRP bar yield strength can be deployed when loaded under compression and tension, respectively.
\end{abstract}

Keywords: High-strength concrete, empirical stress-strain model, fiber-based analysis

\section{INTRODUCTION}

High-strength concrete (HSC) in reinforced concrete (RC) column constructions has been used in many high-rise buildings. By using HSC in RC column, the column size can be reduced and thus increase the floor effective area. However, HSC suffers from high brittleness index and has low ductility. To prevent sudden failure in HSC RC column, confinement to the concrete core can be used. In Indonesia, the availability of high-strength bars with strength more than $500 \mathrm{MPa}$ was found to be rare. Hence, to confined HSC RC column using mild steel bar would not be possible without forming a dense arrangement of the confinement and creates weak planes between the concrete core and the cover $[1,2]$. This weak plane can trigger early cover spalling. For a small column, the cover elements occupied quite large area of the whole cross section. Hence, the effect of early cover spalling can be devastating and sudden loss in the axial load carrying capacity will be more pronounce for small column.

As an alternative to replace high-strength reinforcement, a Glass Fiber Reinforced Polymer (GFRP) based bar can be used. This GFRP bar can have yield strength above $1000 \mathrm{MPa}$. GFRP bars does not corroded and hence more suitable to be used as the main reinforcement for concrete structure in the extreme environment. It is light weight and have high resistance per density ratio. However, this GFRP bar is considered as anisotropic material which behaves differently under different load directions and is not possible to utilize its maximum yield or rupture strength. GFRP bar can achieve $13 \%$ higher strength and $58 \%$ yield strain than the conventional bar [1]. One of the major drawbacks of using GFRP bar is the low elastic modulus compared to steel. Toutanji and Saafi [2] reported that larger crack width and deflection was observed when testing $\mathrm{RC}$ beam reinforced with GFRP bar compared to RC beam reinforced with conventional steel.

${ }^{a}$ Civil Engineering Department, Institut Teknologi Sepuluh Nopember, Sukolilo, Surabaya 60111, Indonesia. Corresponding author email address: piscesa@ce.its.ac.id
The strength for GFRP bar under compression and tension is not similar. The compressive strength of GFRP bar is much less than its tensile strength. Husain et. al [3] noted that the compressive strength of GFRP bar is only 40 to $60 \%$ of its tensile strength. Furthermore, ACI 440.1R-06 also noted that FRP bars should not be used for concrete structure under compression. CAN/SCA S806-12 [4] does not consider the FRP bar contribution for compression members. In ACI 440 1R.15, there was no guide provided for compression members made of FRP bars.

Afifi et. al [5] and Tobbi et. al [6] examined NSC circular and rectangular GFRP RC column. From their investigation, it was reported that within the same reinforcing area and configuration, the GFRP bar contribution to resist compression was about 3 to 10 percent of its axial load capacity. On the other hand, the column with conventional steel gives about 12 to 16 percent contribution which was higher than the GFRP bar. Tobbi et. al [7] also reported that the optimal strength adjustment value for GFRP bar under compression is only 35 percent of its tensile strength capacity [8]. On the other hand, Xue et. al [9] noted that the reduction of the axial load carrying capacity of GFRP RC column under eccentric loading was found to be insignificant, but it did shows higher lateral deformation. Salah-Eldin et. al [4], noted that the utilization of GFRP bar in HSC RC column did not show any significant difference in terms of axial strength compared to the conventional bar. It was also reported that the GFRP RC ductility was higher than the conventional one when loaded under coequal loads and eccentricity. Hadi et. al [10] tested 12 HSC RC circular column with GFRP bars. It was found out that the column can withstand almost the same axial load when loaded under concentric compression. However, the axial ductility was significantly reduced up to $30 \%$. In addition, as the load eccentricity increases, the axial load carrying capacity decreases.

From a brief literature review, it can be concluded that the use of GFRP bar for RC column still contradicted each other and are subjected for further discussion. For that 
purpose, in this paper, an inverse analysis method based nonlinear finite element simulation was carried out to determine the correct strength adjustment for GFRP bar under compression and tension load for RC column under concentric loading. For that purpose, an inhouse 3DNLFEA package will be used in the numerical simulation.

\section{RESEARCH SIGNIFICANCE}

This paper investigates the nonlinear behavior of RC column made of HSC and built up with conventional steel and GFRP bar. One of the significances finding in this paper is that the axial stress for GFRP bar under compression and tension should be reduced up to 25 and $45 \%$ of the ultimate rupture strength of the bar, respectively. By using the assumed reduction of the bar strength, the load-deflection curve was accurately predicted using the 3D-NLFEA software package.

\section{METHODOLOGY}

\section{A. SPECIMEN GEOMETRY AND MATERIAL PROPERTIES}

The modeled specimen was obtained from Hadi et. al [10]. There are two specimens modeled, S60E0 and G30E0. Both specimens were loaded under concentric load. Specimen S60E0 was made of conventional steel while specimen G30E0 was made of GFRP bar. The concrete strength for both columns is $85 \mathrm{MPa}$. The diameter of the column is $210 \mathrm{~mm}$ with $20 \mathrm{~mm}$ cover thickness. Table 1 shows the details of the reinforcing bar configuration.

It should be noted that for conventional steel rebar, the Young's modulus is set to $200 \mathrm{GPa}$. For the GFRP bar reinforcement, the Young's modulus is set to $57 \mathrm{GPa}$ which was based on the test data in [10]. In Table $1, \mathrm{~d}_{\mathrm{b}}$ is the longitudinal bar diameter, $\mathrm{d}_{\mathrm{h}}$ is the confining bar diameter, $\mathrm{s}$ is the pitch spacing, $\mathrm{f}_{\mathrm{y}}$ is the yield strength of the longitudinal bar, and $f_{y h}$ is the yield strength of the confining bar.

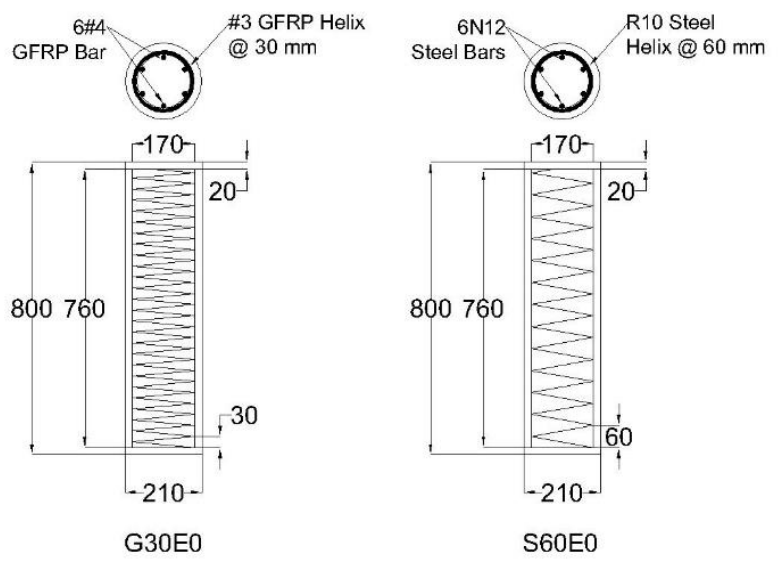

Figure 1. Detail specimen configuration

Table 1. Specimen reinforcing bars

\begin{tabular}{ccccc}
\hline Specimen & $\begin{array}{c}\text { Rebar } \\
\text { Type }\end{array}$ & $\begin{array}{c}\mathrm{d}_{\mathrm{b}} \\
(\mathrm{mm})\end{array}$ & $\begin{array}{c}\mathrm{d}_{\mathrm{h}} @ \mathrm{~s} \\
(\mathrm{~mm})\end{array}$ & $\begin{array}{c}\mathrm{f}_{\mathrm{y}} \mid \mathrm{f}_{\mathrm{yh}} \\
(\mathrm{MPa})\end{array}$ \\
\hline S60E0 & Steel & $6 \mathrm{~N} 12$ & R10@60 & $420 \mid 550$ \\
G30E0 & GFRP & $6 \# 4$ & $\# 3 @ 30$ & $1190 \mid 1320$ \\
\hline
\end{tabular}

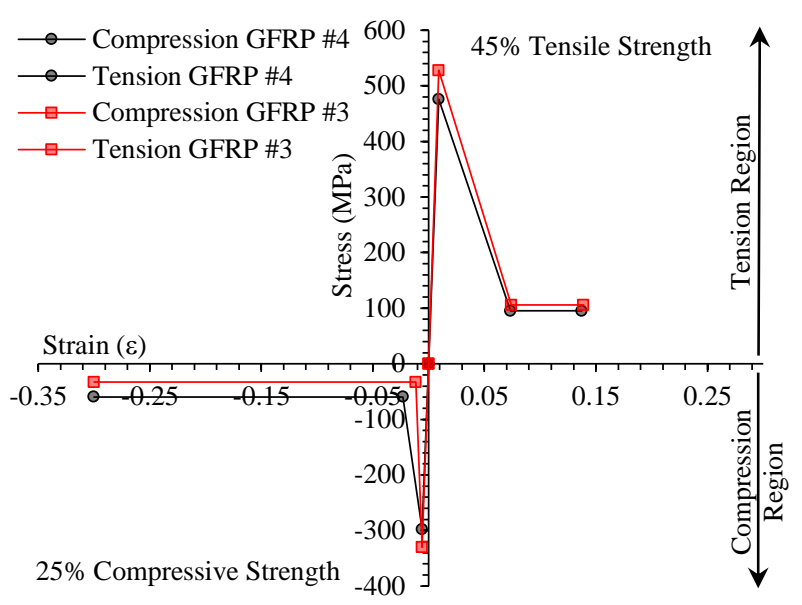

Figure 2. Stress-strain curve of GFRP Bar

For the reduction strength of the GFRP bar under compression, as observed in many test results, the value was varying from $35 \%$ to $60 \%$. During the experimental preparation, the GFRP bar which formed the spiral was bended. Hence, the tensile strength of the GFRP bar was also reduced significantly. This strength reduction is more likely to caused by micro-buckling of the fibers that may occurs when the bar being compressed and bended. Therefore, in this paper, the stress-strain curves used to model the GFRP bars, which are shown in Figure 2, was set to $25 \%$ and $45 \%$ of the GFRP bar yield strength for bars under compression and tension load are used, respectively.

\section{B. 3D-NLFEA FINITE ELEMENT PACKAGE}

The numerical simulations are carried out using 3DNLFEA finite element package $[11,12]$. The pre- and postprocessor are using SALOME 9.3.0 [13] and ParaView 5.8.0 [14-16]. The mesh of solid element is using hexahedral formulation with BBar element technology [17]. The bars element are modelled using embedded formulation [18, 19] with perfect bond assumption. Modified initial stiffness method [20] was used in 3DNLFEA to accelerate the convergence in the global nonlinear iteration. 3D-NLFEA have been used to simulate RC column wrapped with CFRP under eccentric load and was found to be successful in predicting the load-deflection response of the available test result [21].

\section{3D MODEL AND BOUNDARY CONDITIONS}

Figure 3 shows the 3D model of the meshed specimen using SALOME 9.3.0. The solid elements were meshed using hexahedral element. Specimen G30E0 and S60E0 have a total of 25,073 and 25,124 hexahedral elements, respectively. The total embedded rebar element for specimen G30E0 and S60E0 are 2,323 and 1,387, respectively.

In Figure 3a, the concrete core and the cover can be differentiated by looking at the element types. The concrete cover was shown as wireframe while the concrete core was shown as the solid colored element. The boundary condition at both ends was set to be fixed in the lateral direction. The bottom end is restrained to move in the vertical direction while displacement control is given at the top end. The bar configuration for S60E0 was shown in Figure $3 \mathrm{~b}$ while for G30E0 was shown in Figure 3c. It 
should be noted that the pitch spacing for S60E0 was 60 $\mathrm{mm}$ while for G30E0 was $30 \mathrm{~mm}$.

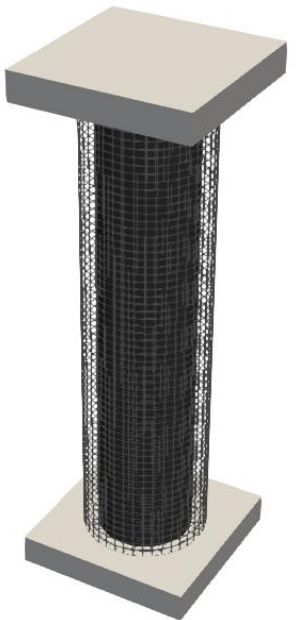

(a)

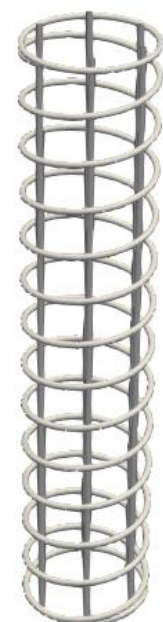

(b)

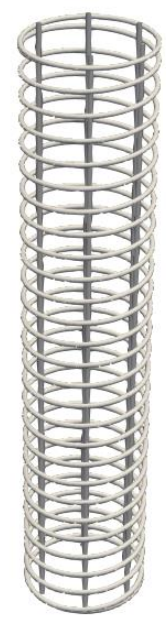

(c)
Figure 3. Modeling of Specimens (a) wire look of concrete cover, blue solid look of concrete core and solid look of concrete core; (b) spiral reinforcement with $60 \mathrm{~mm}$ spacing; (c) spiral reinforcement with $30 \mathrm{~mm}$ spacing

\section{MATERIAL CONSTITUTIVE MODELS}

The solid steel plate is modelled using the Von Mises criterion with elastic-perfectly plastic model. The reinforcing bar model for the conventional steel also follows the elastic-perfectly plastic model. However, for the GFRP bar, the stress-strain model used was based on non-symmetric stress-strain for compression and tension as shown in Figure 2. Perfect bond assumption is used to model the reinforcing bar that are embedded inside the parent element. The concrete constitutive model is based on the plasticity-fracture model developed by Piscesa et. al which is path-dependent [22], restraint sensitive [11, 23, $24]$, and is able to predict premature cover spalling accurately [12]. In [11, 12], the failure surface for concrete under compression is based on the modified Menetrey and Willam $[25,26]$ failure surface.

\section{ANALYSIS AND DISCUSSIONS}

\section{A. LOAD-DEFLECTION RESULTS}

Figure 4 shows the axial load-axial of specimen deflection between experimental and numerical result for specimen S60E0 and G30E0. As shown in Figure 4, the first peak load for both S60E0 and G30E0 were predicted well. The first peak load obtained from the test results for specimen S60E0 and G30E0 were $2719.01 \mathrm{kN}$ and $2395.36 \mathrm{kN}$, respectively. The predicted first peak load using 3DNLFEA for specimen S60E0 and G30E0 are $2710.29 \mathrm{kN}$ ($0.32 \%$ ) and $2517.12 \mathrm{kN}(+5.08 \%)$, respectively.

Both specimens S60E0 and G30E0 shows sudden drop in axial load due to premature cover spalling failure. For specimen S60E0, once the cover spalls, both in the model and the test result showed a second peak due to confinement effect of concrete core. Once the confining bar yields, the load-deflection curve starts to soften again until it reached the residual state. Here, it was reported that there was some discrepancy of the residual load between the test result and numerical model. This can be caused by severe damage in concrete core and buckling of longitudinal bars which may formed due to geometry and material imperfections which were not modelled in the numerical simulation.

On the other hand, specimen G30E0 behavior after the first peak also drop significantly but due to low Young's modulus of the GFRP bar, the increase in the load carrying capacity increases in a much slower rate than S60E0. Both the $2^{\text {nd }}$ peak of S60E0 and G30E0 showed almost the same level. After the GFRP bar strain that used to confine the concrete core reaches $45 \%$ yield strain, the GFRP bar fractured and has lost its load carrying capacity. This resulted in sudden drop without any residual load carrying capacity left for the RC column.

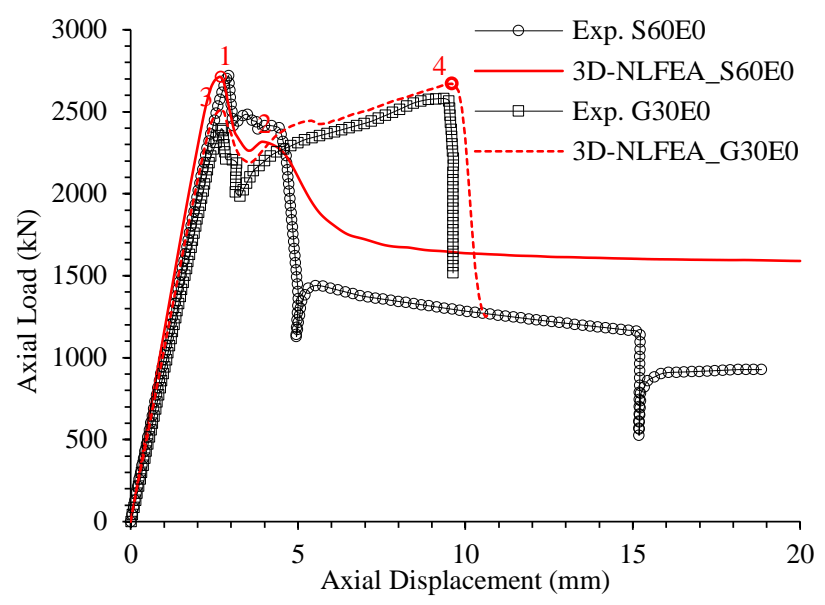

Figure 4. Relation curve of P- $\Delta$ specimen S60E0 and specimen G30E0

\section{B. HARDENING PARAMETER (k)}

In the plasticity-fracture model [12], the hardening parameter $(\mathrm{k})$ relates to the normalized cumulative plastic volumetric strain which have a value of less than unity when the concrete elements hardens and more than unity when it's softens. There are two points observation in the load-deflection curve for each specimen as shown in Figure 4. For specimen S60E0, point 1 and 2 are selected which represent the first and second peak loads. While for specimen G30E0, point 3 and 4 are selected for the same reason as in S60E0. Figure 5 and Figure 6 show the hardening contour plots for specimen S60E0 and G30E0, respectively. From Figure 5 and Figure 6, it was shown that the concrete cover elements suffer from more damage (higher hardening parameter value) compared to the concrete core elements.

\section{VON MISES STRESS DISTRIBUTION}

Figure 7 and Figure 8 show the Von Mises stress distribution for specimen S60E0 and G30E0, respectively. As expected, the Von Mises stress distribution in the concrete cover elements was found to be the lowest at both points' observation. The lower Von Mises stress value can be attributed to higher damage and zero confining pressure 
in the concrete cover elements compared to the concrete core. At point 2 and point 4 for S60E0 and G30E0 specimen, the Von Mises stresses were found to be zero which shows complete spalling of the concrete cover.

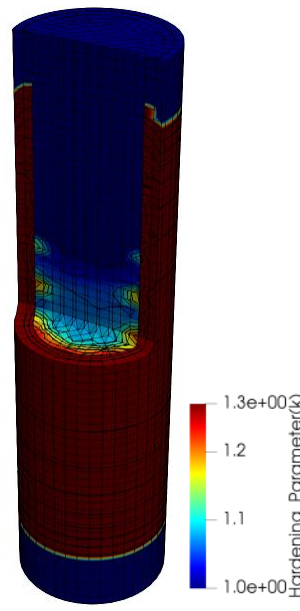

(a)

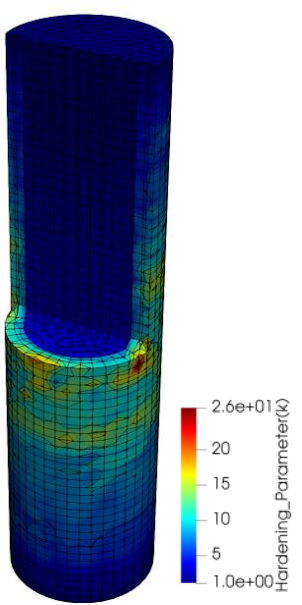

(b)
Figure 5. S60E0 hardening parameter at (a) point 1 and (b) point 2

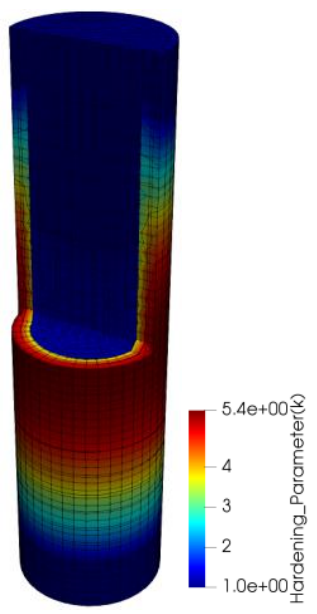

(a)

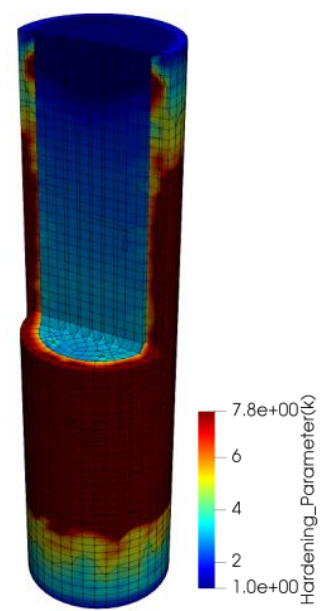

(b)
Figure 6. G30E0 hardening parameter at (a) point 3 and

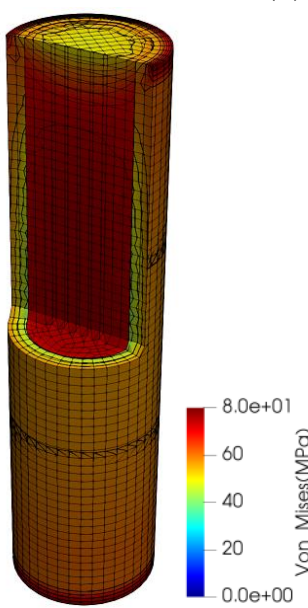

(a)

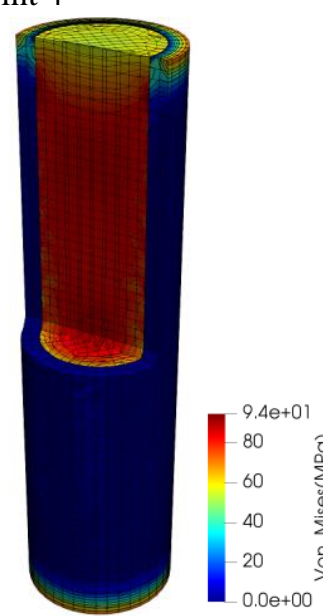

(b)
Figure 7. S60E0 Von Mises stress at (a) point 1 and (b) point 2

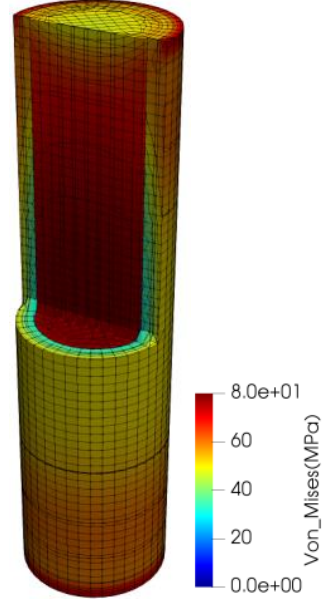

(a)

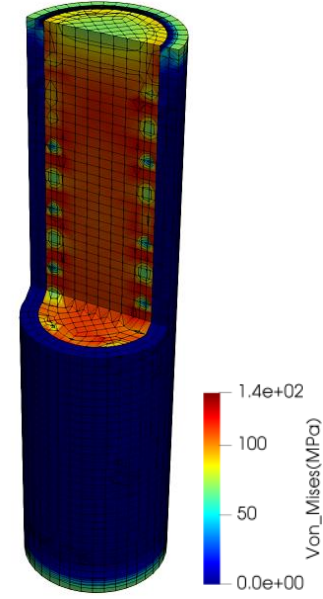

(b)
Figure 8. G30E0 Von Mises stress at (a) point 3 and (b) point 4

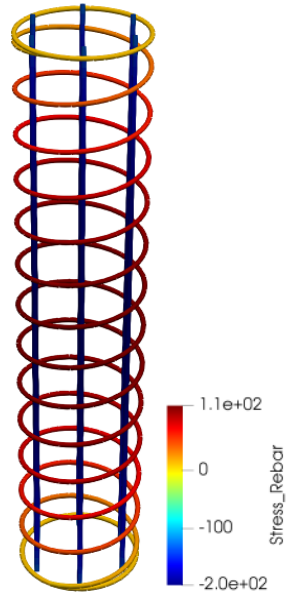

(a)

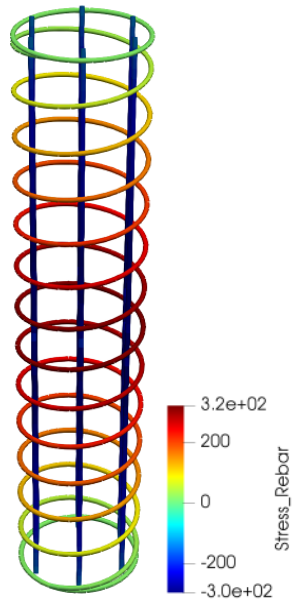

(b)
Figure 9. S60E0 Bar stress at (a) point 1 and (b) point 2

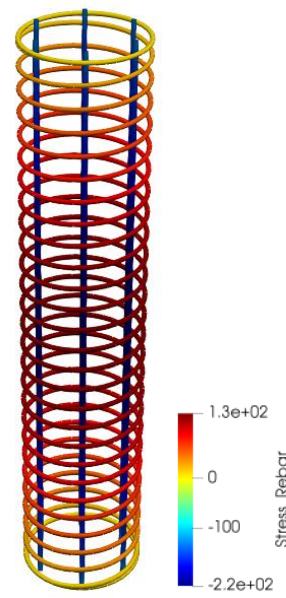

(a)

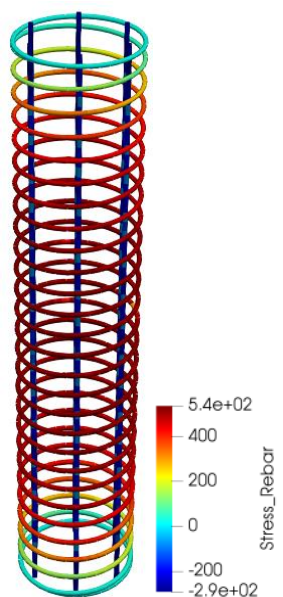

(b)
Figure 10. G30E0 Bar stress at (a) point 3 and (b) point 4 D. REINFORCING BAR STRESSES

Figure 9 and Figure 10 show the reinforcing bar stresses for specimen S60E0 and G30E0, respectively. As shown in Figure 9 and Figure 10, the maximum confining bar stresses occurs at the mid-height of the section due to damage localization. The maximum confining bar stress 
for specimen S60E0, as shown in Figure 9, at point 1 is 110 $\mathrm{MPa}$ and at point 2 is $320 \mathrm{MPa}$ (not yet yielded). The maximum confining bar stress for specimen G30E0, as shown in Figure 10, at point 3 is $130 \mathrm{MPa}$ (softens) and at point 2 is $540 \mathrm{MPa}$ (45\% ultimate tensile strength of GFRP bar).

\section{CONCLUSIONS}

This paper presents numerical simulation using 3DNLFEA to capture the behavior of RC column with GFRP bars. An inverse analysis to get the best match of the load deflection curve between the numerical prediction and the available test result was carried out. From the inverse analysis, it was found out that the compressive capacity of the GFRP bar is only $25 \%$ of its ultimate tensile strength capacity. On the other hand, the tensile strength capacity of the transverse GFRP bar which was curved to create the spirals was only $45 \%$ of its ultimate tensile strength capacity. Hence, for GFRP bar that are curved, there is possibility that the micro buckling of the fiber in the half part of the section was already occurred which lowered the its tensile strength capacity.

The accuracy of the peak load prediction for both specimens using 3D-NLFEA have been presented. The first peak load obtained from the test results for specimen S60E0 and G30E0 were $2719.01 \mathrm{kN}$ and $2395.36 \mathrm{kN}$, respectively. The predicted first peak load using 3DNLFEA for specimen S60E0 and G30E0 are 2710.29 kN ($0.32 \%)$ and $2517.12 \mathrm{kN}(+5.08 \%)$, respectively. Hence, it can be concluded that the accuracy of the numerical model was excellent.

Further research of GFRP made RC column should be carried out by extending the database of the test result accompanied with numerical simulation to further verify the reduced capacity of GFRP bars using the inverse analysis results obtained in this paper. It is also important to look on other loading condition such as eccentrically loaded GFRP RC column and combination of constant axial load with monotonically increased bending moment. Once the reduced capacity of GFRP bars reinforcement is settled, parametric studies using 3D-NLFEA can be generated to study the ductility of GFRP bars which can be used as the basis for design purposes.

\section{REFERENCES}

[1] S. A. A. Jabbar and S. B. H. Farid, "Replacement of steel rebars by GFRP rebars in the concrete structures," Karbala International Journal of Modern Science, vol. 4, no. 2, pp. 216-227, 2018, doi: 10.1016/j.kijoms.2018.02.002.

[2] H. Toutanji and M. Saafi, "Flexural behavior of concrete beams reinforced with glass fiber-reinforced polymer (GFRP) bars," ACI Structural Journal, vol. 97, pp. 712-719, 2000.

[3] S. F. Husain, M. Shariq, and A. Masood, "GFRP Bars for RC structures - A Review," International
Conference on Advances in Construction Materials and Structures, no. March, 2018.

[4] H. M. M. Ashraf Salah-Eldin, Brahim Benmokrane, "Structural performance of high-strength-concrete columns reinforced with GFRP bars and ties subjected to eccentric loads," Engineering Structures, vol. Engineering Structures 185 (2019) 286-300, 2019.

[5] M. Z. Afifi, H. M. Mohamed, and B. Benmokrane, "Axial capacity of circular concrete columns reinforced with GFRP bars and spirals," Journal of Composites for Construction, vol. 18, no. 1, pp. 1-11, 2014, doi: 10.1061/(ASCE)CC.1943-5614.0000438.

[6] H. Tobbi, A. S. Farghaly, and B. Benmokrane, "Strength model for concrete columns reinforced with fiber-reinforced polymer bars and ties," ACI Structural Journal, vol. 111, no. 4, pp. 789-798, 2014, doi: 10.14359/51686630.

[7] H. Tobbi, A. S. Farghaly, and B. Benmokrane, "Concrete columns reinforced longitudinally and transversally with glass fiber-reinforced polymer bars," ACI Structural Journal, vol. 109, no. 4, pp. 551558, 2012, doi: 10.14359/51683874.

[8] K. Kobayashi and T. Fujisaki, "32 compressive behavior of FRP reinforcement in non-prestressed concrete members," in Non-Metallic (FRP) Reinforcement for Concrete Structures: Proceedings of the Second International RILEM Symposium, 1995, vol. 29: CRC Press, p. 267.

[9] W. Xue, X. Hu, and Z. Fang, "Experimental studies of GFRP reinforced concrete columns under static eccentric loading," in 7th International Conference on Fiber Reinforced Polymer (FRP) Composites in Civil Engineering (CICE 2014), International Institute for FRP in Construction (IIFC), Kingston, ON, Canada, 2014, pp. 236-242.

[10] M. N. S. Hadi, H. A. Hasan, and M. N. Sheikh, "Experimental investigation of circular high-strength concrete columns reinforced with glass fiberreinforced polymer bars and helices under different loading conditions," Journal of Composites for Construction, vol. 21, no. 4, pp. 1-13, 2017, doi: 10.1061/(ASCE)CC.1943-5614.0000784.

[11]B. Piscesa, M. M. Attard, and A. K. Samani, "3D Finite element modeling of circular reinforced concrete columns confined with FRP using a plasticity based formulation," Composite Structures, vol. 194, pp. 478-493, 2018.

[12] B. Piscesa, M. M. Attard, D. Prasetya, and A. K. Samani, "Modeling cover spalling behavior in high strength reinforced concrete columns using a plasticity-fracture model," Engineering Structures, vol. 196, p. 109336, 2019.

[13] E. R. Cea/Den and O. C. D, "SALOME version 9.3.0," SALOME - The open source integration 9.3.0;, platform for numerical simulation http://www.salomeplatform.org/Ver. Http://www.salome-platform.org/., 2019. [Online]. Available:https://files.salomeplatform.org/Salome/Salome9.3.0/SALOME_9_3_O_ Release_Notes.pdf, no. May, pp. 1-24, 2019.

[14] J. Ahrens, B. Geveci, C. Law, J. Ahrens, B. Geveci, and C. Law, "ParaView : An End-User Tool for Large Data Visualization," vol. 836. 
[15] J. Ahrens, B. Geveci, C. Law, C. Hansen, and C. Johnson, "36-ParaView: An End-User Tool for LargeData Visualization," The Visualization Handbook, p. 717, 2005.

[16]U. Ayachit, "The paraview guide: a parallel visualization application," 2015.

[17] T. J. Hughes, The finite element method: linear static and dynamic finite element analysis. Courier Corporation, 2012.

[18]A. Ranjbaran, "Embedding of reinforcements in reinforced concrete elements implemented in DENA," Computers \& structures, vol. 40, no. 4, pp. 925-930, 1991.

[19]A. Ranjbaran, "Mathematical formulation of embedded reinforcements in 3D brick elements," Communications in numerical methods in engineering, vol. 12, no. 12, pp. 897-903, 1996.

[20] H. K. Dang, T. Yacoub, J. Curran, M. Visser, and D. Wai, "Evaluate the performance of an accelerated initial stiffness method in three dimensional finite element analysis," Computers and Geotechnics, vol. 62, pp. 293-303, 2014.

[21] A. B. Christianto, B. Piscesa, F. Faimun, and P. Aji, "Finite Element Modeling of Circular Reinforced Concrete Column Confined with CFRP under Eccentric Loading," Journal of Civil Engineering, vol. 34, no. 2, pp. 49-54, 2019.

[22]B. Piscesa, M. Attard, A. Samani, and S. Tangaramvong, "Plasticity Constitutive Model for Stress-Strain Relationship of Confined Concrete," ACI Structural Journal, vol. 114, no. 2, p. 361, 2017.

[23] B. Piscesa, M. M. Attard, and A. K. Samani, "A lateral strain plasticity model for FRP confined concrete," Composite Structures, vol. 158, pp. 160-174, 2016.

[24] B. Piscesa, M. M. Attard, and A. K. Samani, "Plastic Dilation Rate Characteristic of Concrete Confined with Steel Tube," in XIV International Conference on Computational Plasticity. Fundamentals and Applications (COMPLAS), Barcelone, Spain, 5-7 September 2017.

[25] P. Menetrey and K. Willam, "Triaxial failure criterion for concrete and its generalization," ACI structural Journal, vol. 92, no. 3, 1995.

[26] V. K. Papanikolaou and A. J. Kappos, "Confinementsensitive plasticity constitutive model for concrete in triaxial compression," International Journal of Solids and Structures, vol. 44, no. 21, pp. 7021-7048, 2007. 